Past farmers and the environment: Insights from Sub-Saharan Africa

\section{Jerry Olatoyan}

Sub-Saharan Africa is an exciting place to investigate the interaction between past farmers and the environment. More than $\mathbf{4 0 0 0}$ years ago, early farmers in this region started planting indigenous crops like pearl millet, sorghum, yam, and Bambara groundnut before introducing crops like maize and cassava around $\mathbf{5 0 0}$ years ago. In the process, farmers interacted with many elements of the environment such as the landscape, vegetation, climate, and soils, and with time, humans began to have an ever-increasing effect on the environment. While some farmers managed to use sustainable methods of farming, the clearing of vegetation before planting crops often destroyed a lot of trees and changed the face of the landscapes, and as a result, some plants became extinct. Also, forests were destroyed and, in many cases, grasses and scanty trees regrew in their place (Fig. 1). A present-day example is from Mpumalanga in South Africa, where about $36 \%$ of the grassland and savanna biomes have disappeared mainly due to farming. ${ }^{1}$
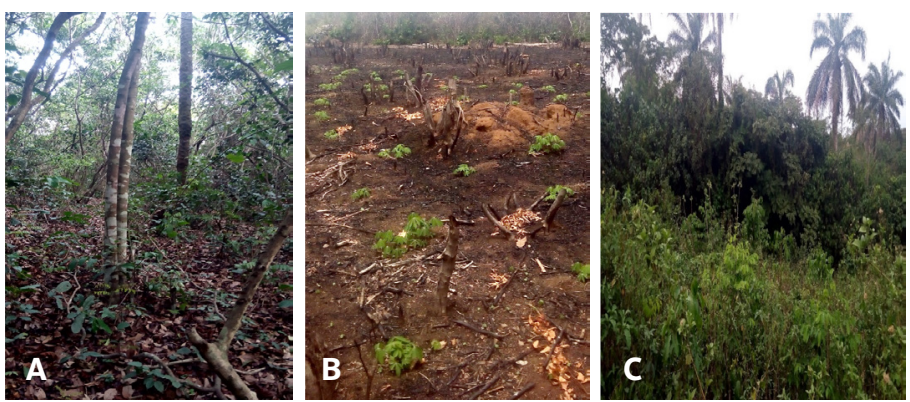

Figure 1: Example of changing landscapes in Ogun State, southwestern Nigeria: (A) A relatively undisturbed forest; (B) Removal of trees by cutting; (C) Regrowth of forest with scanty trees and grasses (Image credit: Jerry Olatoyan).

The transition to crop farming that took place about 4000-5000 years ago was a remarkable event in the history of Sub-Saharan Africa and gave rise to a new economy and livelihood. Prior to this, humans had been hunters and/ or gatherers for a long time (Fig. 2). This transition occurred at different times in different parts of this region due to migration, available wild resources, dominant vegetation types, climatic conditions, and a settled way of life. These factors were often responsible for the early or later beginning of crop farming as they either facilitated, hindered, or delayed the process. For example, while the direct evidence
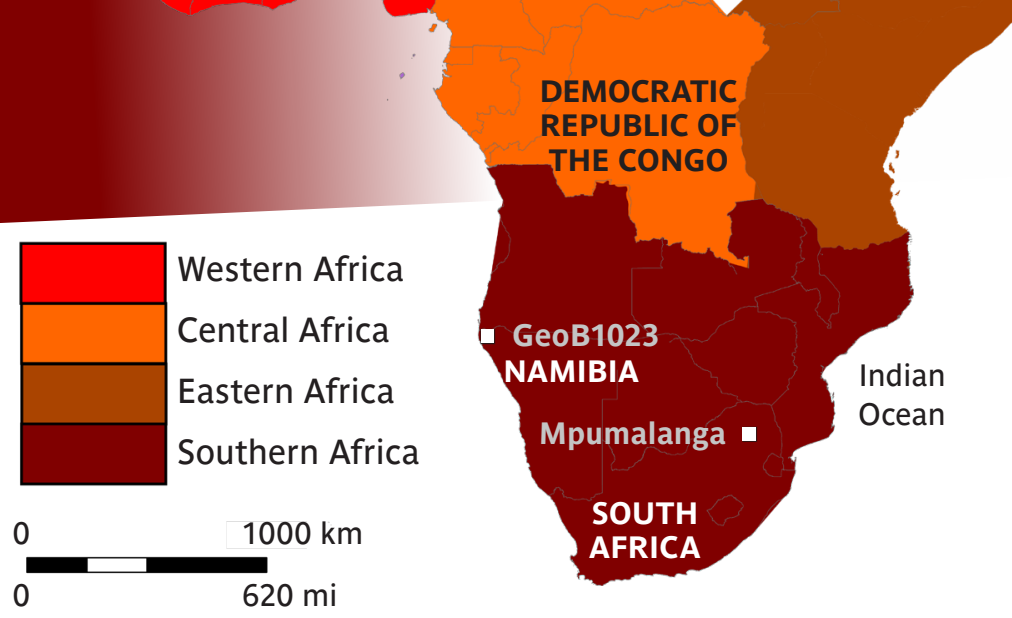

of the first sowing of tuber and root crops is still missing in the records, current evidence shows that cereal farming started around 2500 BCE in western Africa, 700 BCE in central Africa, and not until after $200 \mathrm{CE}$ in eastern and southern Africa. ${ }^{2,3,4}$ Since humans then had to wait for the harvest, they became less mobile, built semi-permanent or permanent settlements, and the population began to increase.

Also, around this time, iron and copper production became widespread, and this technological development is often associated with crop farming. With this technology, humans were able to produce tools like hoes and sickles to improve farming, as well as weapons such as spears to conquer territories and expand their kingdoms. However, the processes of producing these tools and weapons often led to the destruction of forests because they required enormous amounts of wood for charcoal (Fig. 3). An experiment in 2007 showed that approximately $228 \mathrm{~kg}$ (503 lbs) of charcoal from wood were required to process $40 \mathrm{~kg}$ (90 lbs) of ore in one furnace. ${ }^{5}$
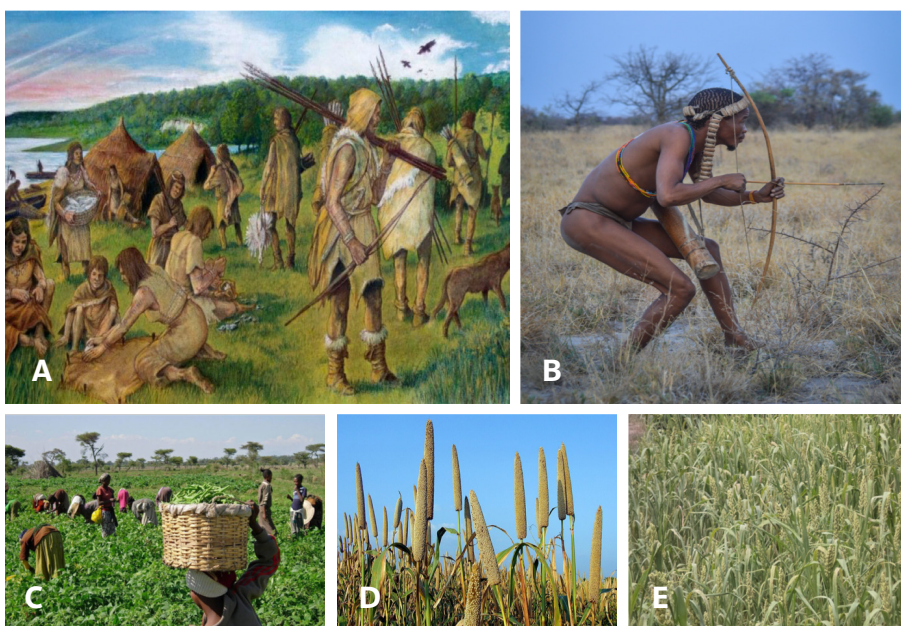

Figure 2: (A) A typical hunting and gathering ceremony (Ethelene Bailey, dualdove.com); (B) Use of the bow and arrow for hunting by a present-day San hunter from southern Africa (Andy Maano); (C) A typical crop farming economy (Ummaimah Dikko, fmic.gov.ng/agricultural-in); (D) Cultivation of pearl millet; (E) Cultivation of sorghum (Saranyanithi). 
Figure 3:

Steps involved in charcoal and iron production:

(A) Stacked wooden logs;

(B) Slow combustion of the wood;

(C) Charcoal produced by combustion;

(D) Iron ore reduction using a traditional furnace; (E) Spongy iron (bloom).
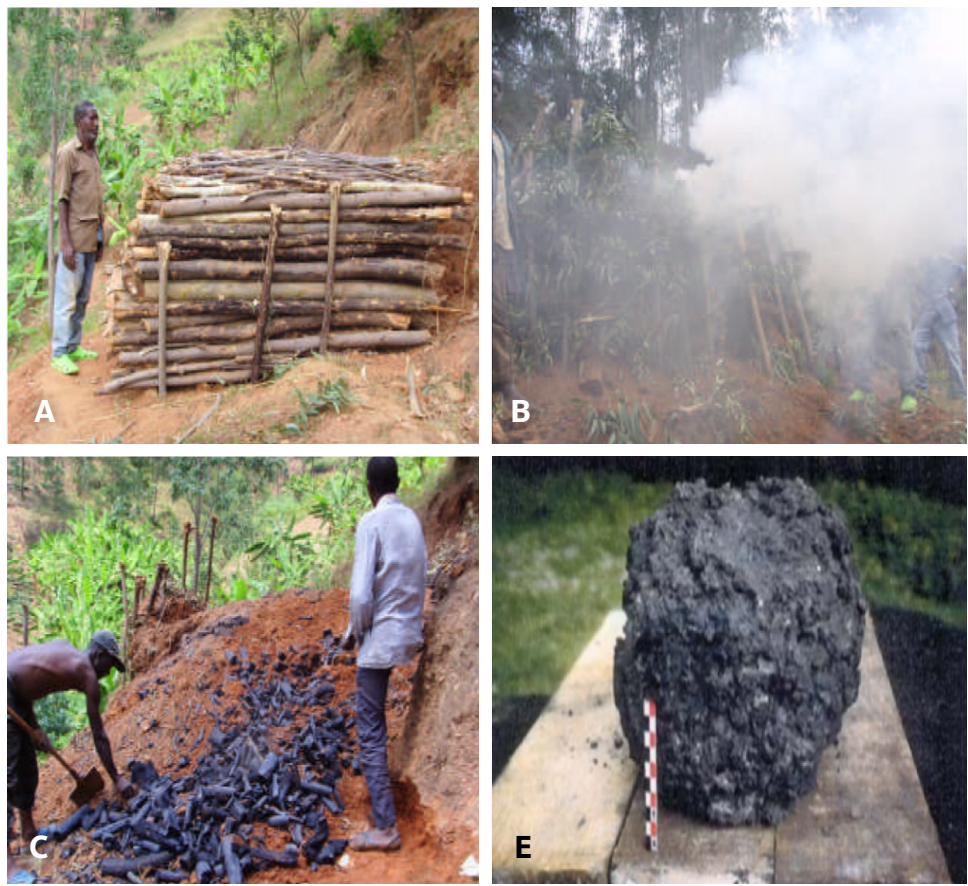

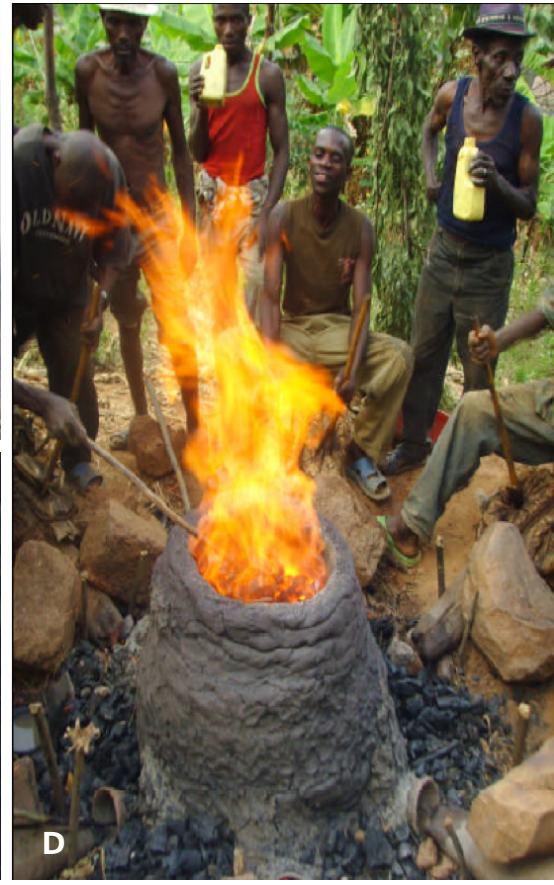

youtube.com/watch?v=SPU8Uwa-jBQ
Let's now look at how we study the impacts and changes on the environment caused by humans. The information about the environment is accumulated in layers over time that are found in natural archives such as lakes, peats, bogs, springs, swamps, and speleothems. These archives serve as the memory of nature, which must be protected. This is why studying paleosciences is important, as it promotes discovery and preservation of the hidden stories in these archives.

To retrieve the information from these archives, we use drilling equipment (e.g. a corer; Fig. 4) to collect sediments, which are then transported to the laboratory for analysis of pollen and charcoal. The sediments collected are sliced into chunks at specific intervals (Fig. 4), followed by physical (i.e. sieving), mechanical (i.e. centrifugation), and chemical (i.e. using $\mathrm{HCl}, \mathrm{HF}, \mathrm{KOH}$, acetolysis mixture) treatments. These allow us to extract the residue, containing microscopic pollen grains and bits of charcoal to be analyzed under the light microscope. After careful study,

Figure 4: (A) This researcher is using a Russian corer to bore into the fen and recover the layered sediments (core); (B) The recovered core with its layers visible; (C) How we slice the core into chunks before processing (University of Melbourne Palaeoecology-Palaeoclimatology).
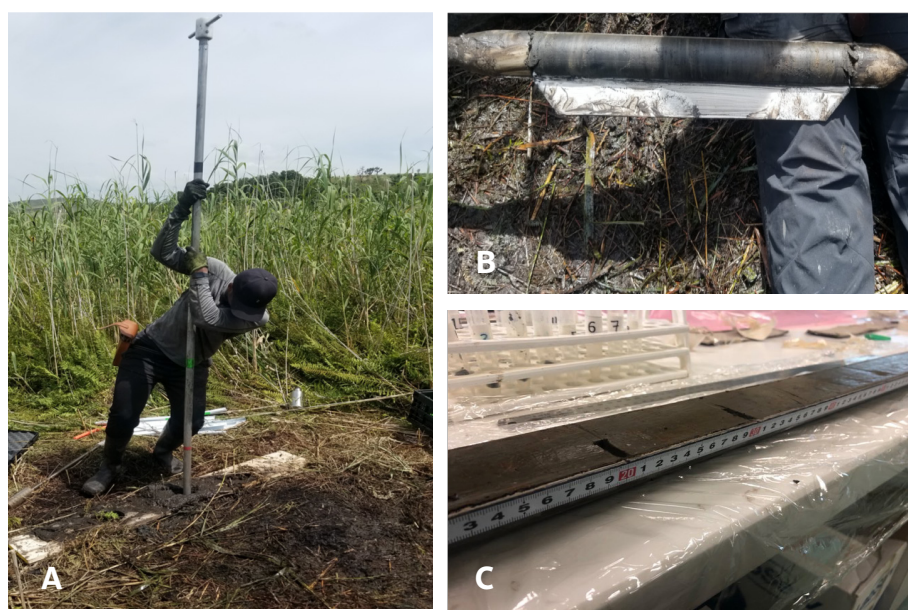

\section{Activity}

Remains of 500 furnaces were found at a site in Ogun State, southwestern Nigeria. Using the data from the above experiment where $40 \mathrm{~kg}$ (90 lbs) of ore in one furnace required $228 \mathrm{~kg}$ (503 lbs) of charcoal, try to estimate the amount of wood that would have been used for the 500 furnaces to each produce $40 \mathrm{~kg}$ ( $90 \mathrm{lbs}$ ) of ore, given that $150 \mathrm{~kg}$ (330 lbs) of charcoal are produced from $600 \mathrm{~kg}$ (1320 lbs) of firewood. ${ }^{6}$

Now estimate the number of acres of forest that would have been destroyed to produce this amount of wood, given that 1 ha $(2.5 \mathrm{ac})$ in tropical rain forests produces an average of $21,250 \mathrm{~kg}(46,850 \mathrm{lbs})$ of wood. ${ }^{7}$

we can identify the cultivated crops and weeds in the region of the core which enables us to have a better idea of the changes in vegetation caused by humans. Also, we can differentiate between the changes caused by climate and those driven by humans by combining two or more data sources that reflect human influence over a given period. For example, the analysis of pollen and charcoal in samples from the GeoB1023 site in Namibia, showed the disappearance of Afromontane forest (e.g. Podocarpus), increase of weed pollen (e.g. Tribulus), and charcoal particles (Fig. 5) beginning from $200 \mathrm{CE}$, which suggests that the inhabitants of this region were transitioning to crop farming around 2000 years ago. ${ }^{8}$
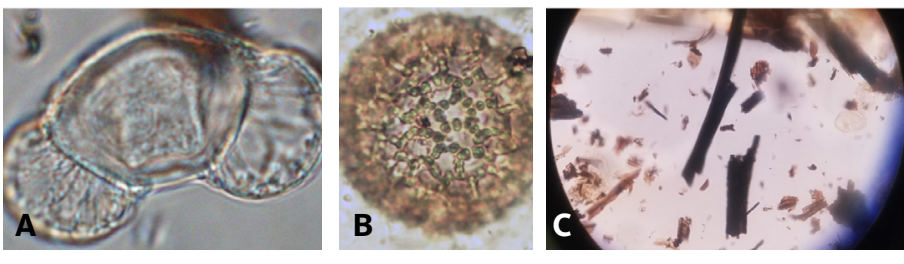

Figure 5: (A) Podocarpus pollen; (B) Tribulus pollen; 9 (C) Microcharcoal particles. 
Finally, as humans continue to practice farming over time, the climate also experiences tremendous changes that in turn affect the production yields of crops. However, farmers have learned how to modify the landscape in order to adapt to the effects of these changes. In northeastern South Africa, for example, farmers that lived between the 16th and 19th centuries used stones to build terraces (raised areas; Fig. 6), to reduce soil and water erosion while conserving the available soil nutrients and soil moisture for maximum use..$^{10}$ This is indeed one of the sustainable ways to adapt to changing environmental conditions locally and further indicate clear evidence of an advanced farming system practiced in pre-colonial times.

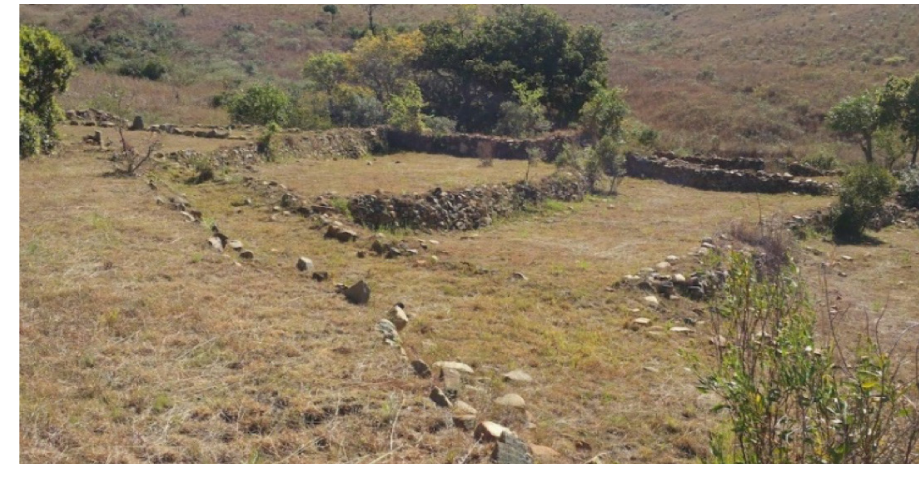

Figure 6: Farming terracing (James Ball, The Heritage Portal, theheritageportal.co.za).

\section{PAST FARMERS and the ENVIRONMENT: INSIGHTS FROM SUB-SAHARAN AFRICA}

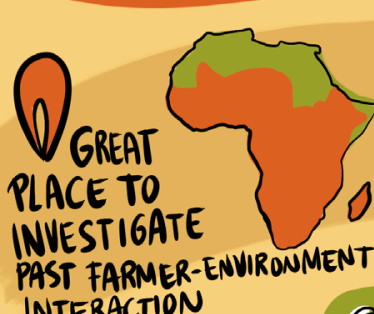
INTERACTION

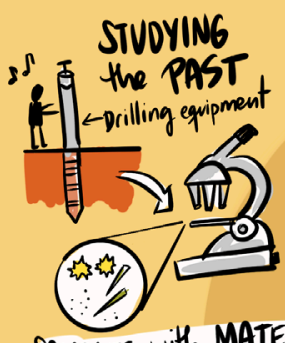

SAMPLES with MATERIALS to RECONSTRUCT EVENTS (pollen, charwal, etc)

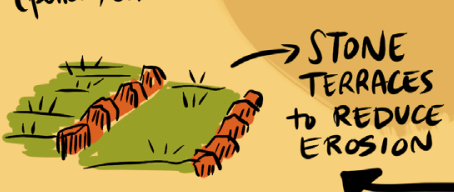

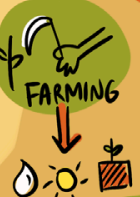
O. ENUIRONMENT
CHANGES but PAST
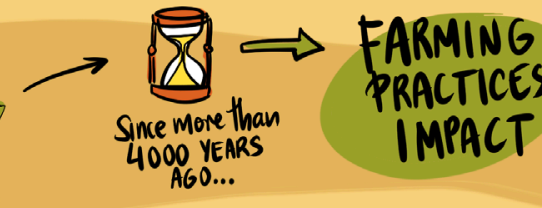
IMPACT
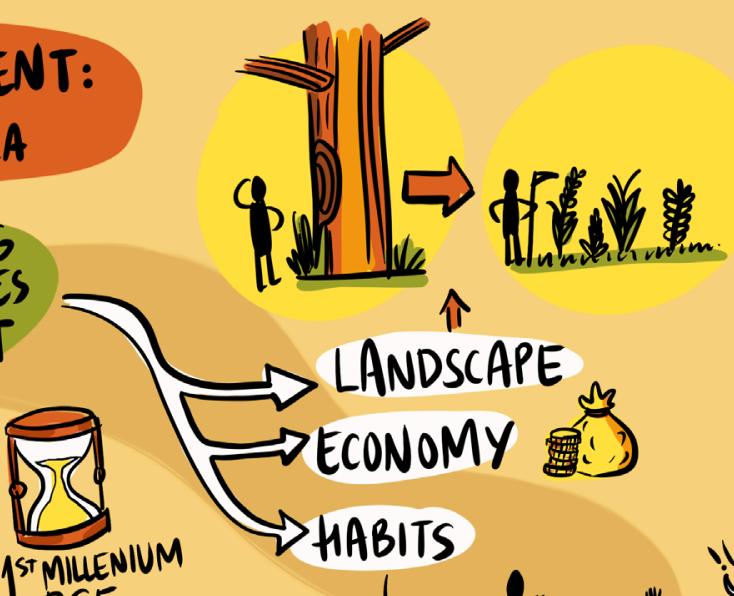

介 LANDSCAPE ? LOTS OF WOOD

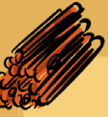
- Giron RODUCTON BCE
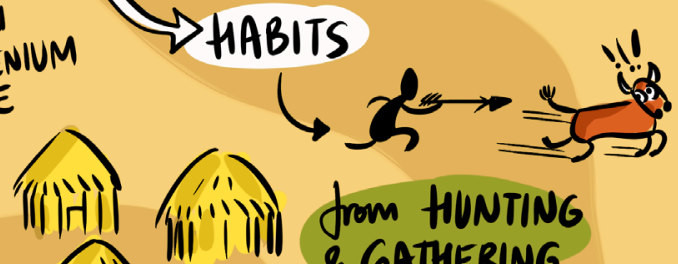
FARMING
TOOSS FARMERS also used

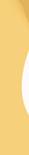
\& conaVer-TERRITORY CONaVER-TERTI
TDOLS ADVANCED\&SUSTAINABLE SYSTENS TO ADAPT to the ENVIRONMENT MiIilithen SETIL to FARM

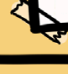
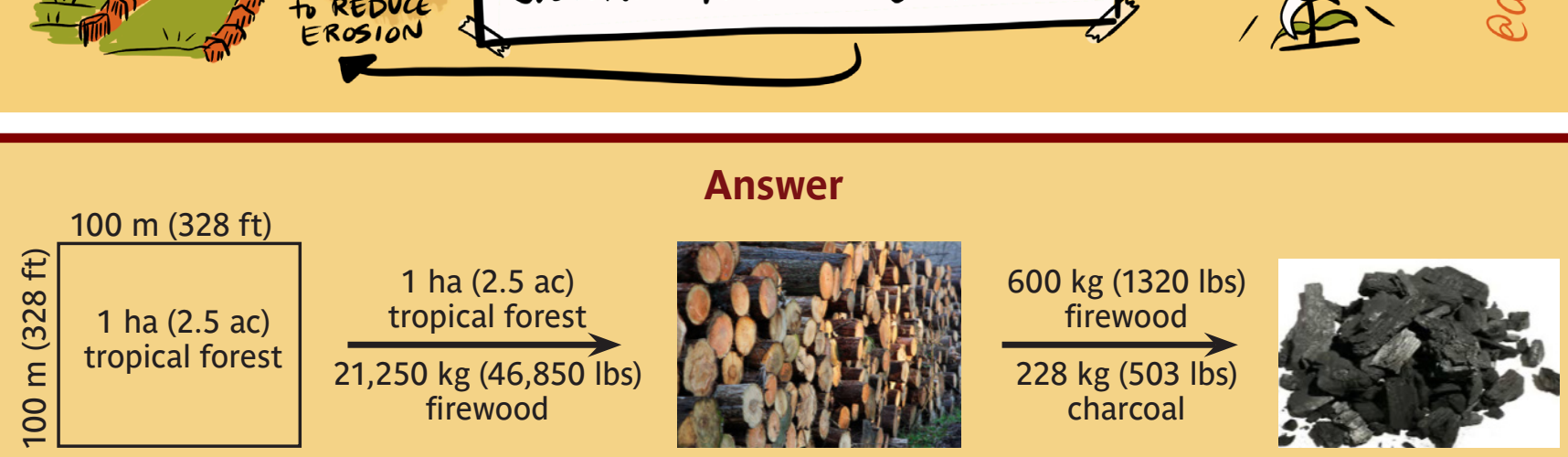

To approximate the amount of firewood that 500 furnaces would have required, we can calculate:

500 furnaces $\times 228 \mathrm{~kg}$ charcoal $/$ furnace $\times 600 \mathrm{~kg}$ firewood $/ 150 \mathrm{~kg}$ charcoal $=456,000 \mathrm{~kg}$ firewood 500 furnaces $\times 503 \mathrm{lbs}$ charcoal/furnace $\times 1320 \mathrm{lbs}$ firewood $/ 330 \mathrm{lbs}$ charcoal $=1,006,000 \mathrm{lbs}$ firewood

This can be used to calculate the area of tropical forest that would have been required:

$456,000 \mathrm{~kg}$ firewood $\times 1$ ha forest $/ 21,250 \mathrm{~kg}$ firewood $=\mathbf{2 1 . 5}$ ha forest

$1,006,000 \mathrm{lbs}$ firewood $\times 2.5 \mathrm{ac}$ forest $/ 46,850 \mathrm{lbs}$ firewood $=\mathbf{5 3 . 7}$ ac forest

That's about the size of 40 football fields! 